\title{
O futuro da energia nuclear
}




\section{JOSÉ GOLDEMBERG}

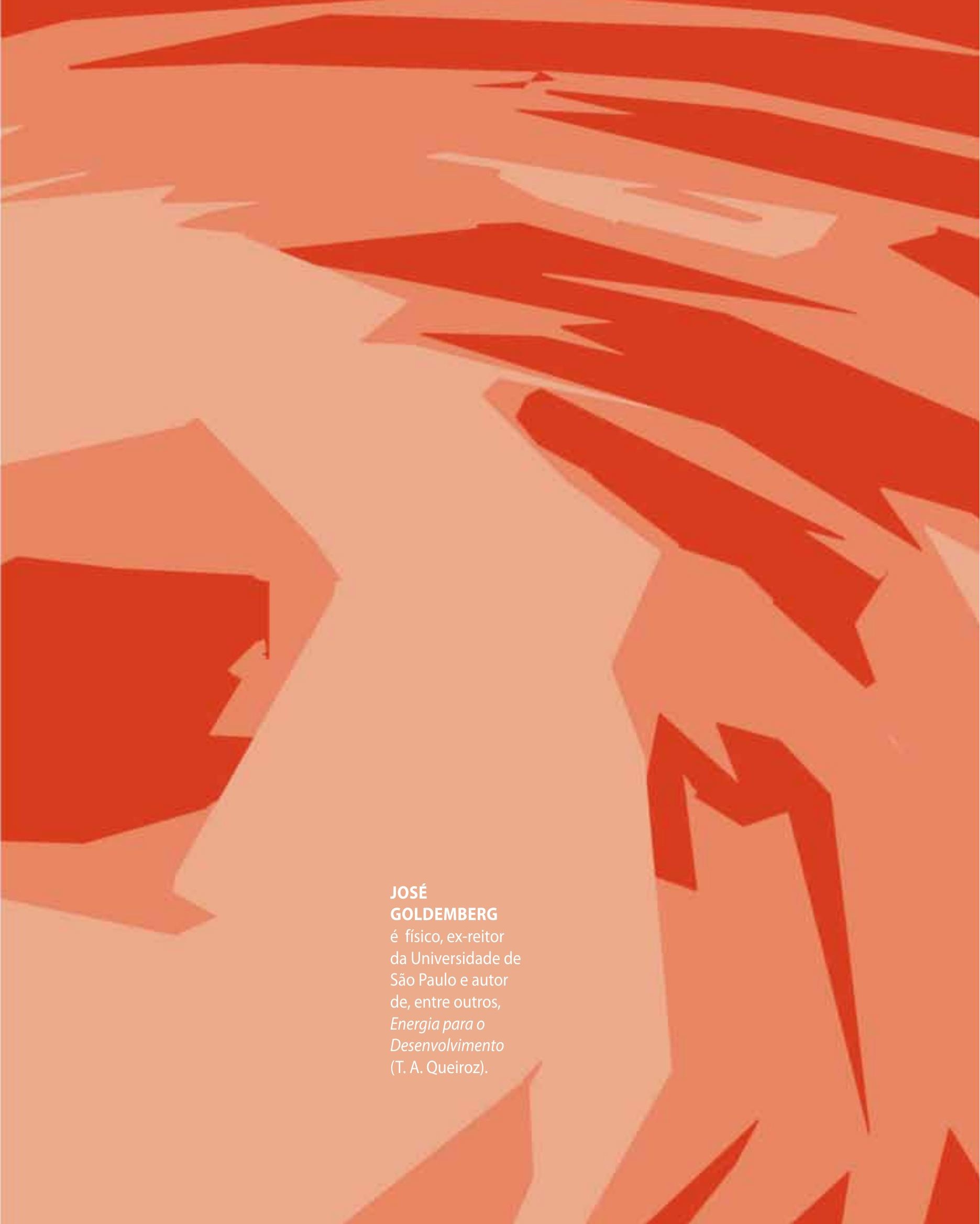




\section{RESUMO}

O presente artigo discute o fenômeno da estagnação da energia nuclear no mundo. As causas são múltiplas e complexas, desde resistências sociais a elevados custos econômicos, passando pelos riscos ambientais ainda não equacionados, como mostrou o recente caso de Fukushima-Daiichi no Japão. As tentativas de promover a energia nuclear minimizando seus impactos se baseiam em argumentos aqui discutidos: baixa probabilidade de ocorrência, poucas mortes sob o aspecto estatístico, possibilidade de melhorias tecnológicas e de gerenciamento de resíduos e aspectos de governança. Em seguida, discute-se o papel da energia nuclear no Brasil à luz dos planos nacionais de energia.

Palavras-chave: energia nuclear, sustentabilidade, Brasil.

\section{ABSTRACT}

This article addresses the phenomenon of the world's nuclear energy stagnation. There are manifold and complex causes, from social resistances to high economic costs, and also environmental risks yet to be assessed, as the recentevent in Fukushima-Daiichi in Japan has shown us. The attempts to promote nuclear energy and minimize its impacts are grounded on arguments discussed here: low probability of occurrence, low death toll statistically speaking, possibility of technological betterment and management of waste and governance aspects. Then we will discuss the role of nuclear energy in Brazil in the light of the national energy plans.

Keywords: nuclear energy, sustainability, Brazil. 


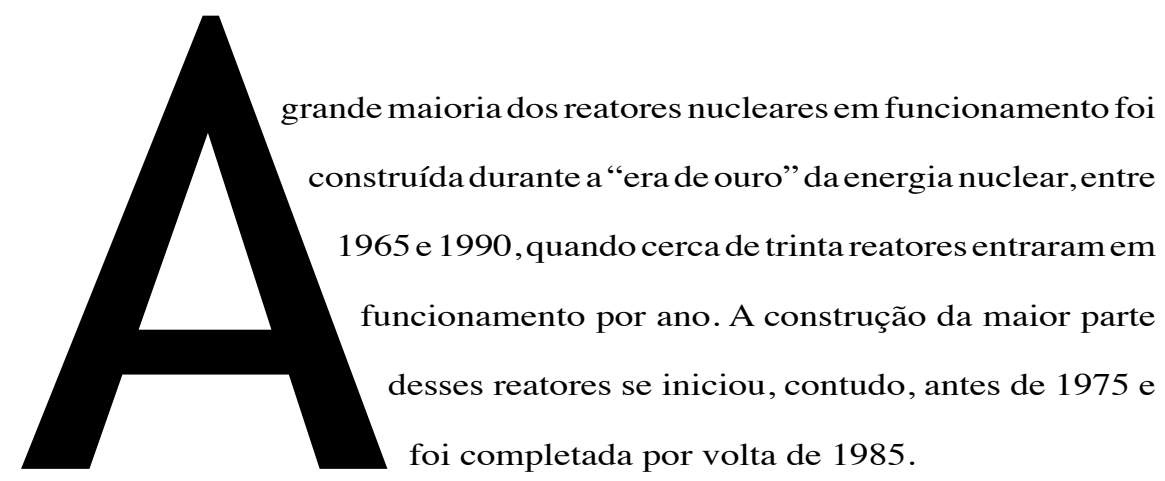

A expansão da energia nuclear no mundo após 1985 foi seriamente abalada pelo acidente de Three Mile Island, na Pensilvânia, Estados Unidos, em 1979. Na ocasião o núcleo de um reator do tipo PWR (reator a água leve pressurizada) fundiu devido a um defeito do sistema de resfriamento, o que, combinado com erros humanos dos operadores do reator, levou à liberação de uma quantidade pequena de radioatividade na atmosfera, principalmente iodo e césio radioativos. Apesar de pequeno, o acidente gerou grandes preocupações na população americana.

Em 1986 ocorreu o desastre de Chernobyl, que lançou na atmosfera (e nas áreas vizinhas ao reator) uma imensa quantidade de radioatividade, aproximadamente 400 vezes a quantidade liberada em Hiroshima. O reator de Chernobyl era muito diferente dos reatores usados no resto do mundo e muito menos protegido, mas ele mostrou o quão sério pode ser um acidente nuclear. Até hoje, uma área de 3.000 quilômetros quadrados em torno da usina é inabitada.

Após os acidentes de Three Mile Island (EUA, 1979) e Chernobyl (URSS, hoje Ucrânia, 1986), sérias preocupações levaram a uma redução considerável no número de reatores que entraram em funcionamento: cerca de três reatores por ano, ou seja, a expansão da energia nuclear estagnou.

No ano 2010 as usinas nucleares geraram cerca de $16 \%$ da eletricidade mundial. A maioria dos 440 reatores nucleares em operação no mundo está na Europa Ocidental, Estados Unidos e Japão, onde $64 \%$ de toda a energia nuclear mundial é gerada, e na ex-URSS. A capacidade instalada total é de cerca de $374 \mathrm{GW}$, aproximadamente igual à produzida pelas usinas hidroelétricas . 


\section{GRÁFICO 1 \\ Reatores em operação: capacidade instalada}

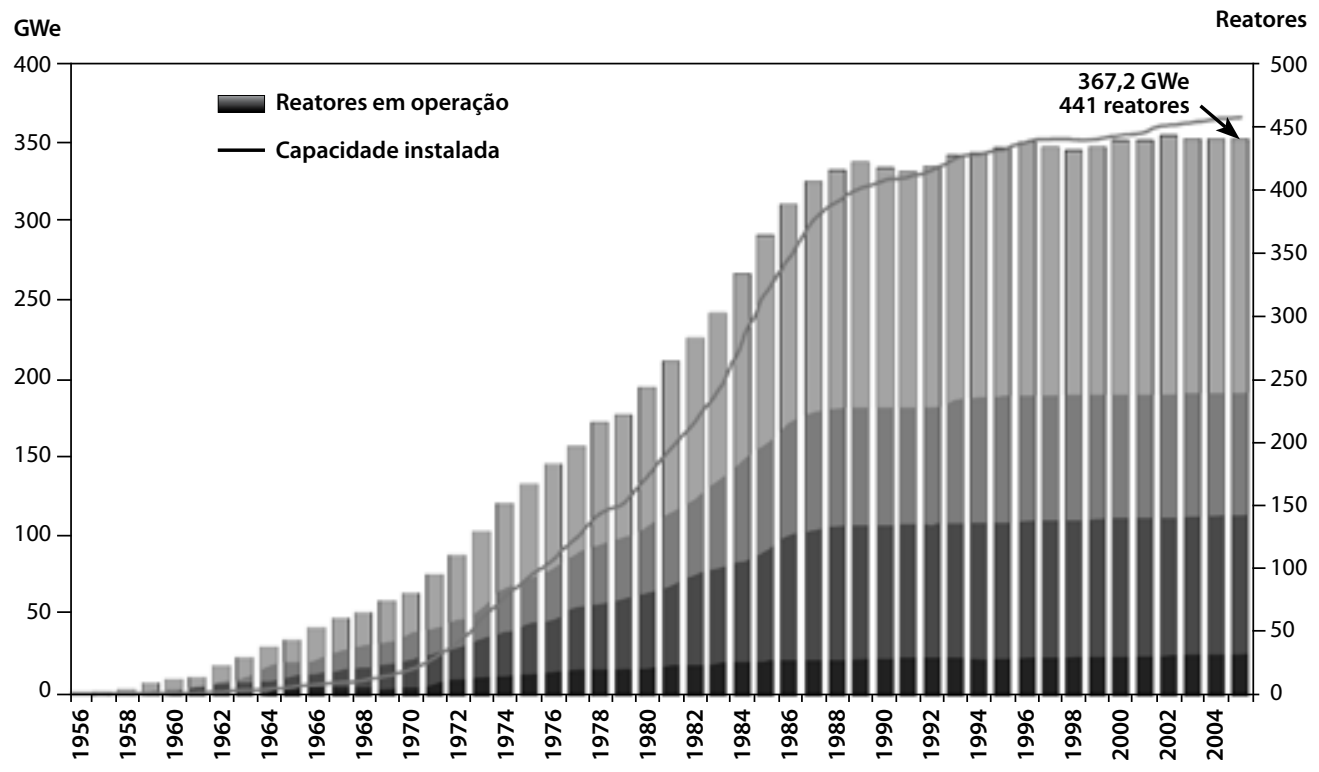

As causas dessa estagnação nuclear são complexas: por um lado, a resistência da população preocupada com os riscos da energia nuclear e, por outro, razões mais pragmáticas, como o custo crescente dessa energia.
Como ocorre com outras tecnologias, esperava-se que o custo de instalação de reatores nucleares por quilowatt decrescesse à medida que mais reatores fossem construídos. Com a energia nuclear isso não aconteceu: os custos aumentaram devido às

GRÁFICO 2

Início de construção de novos reatores

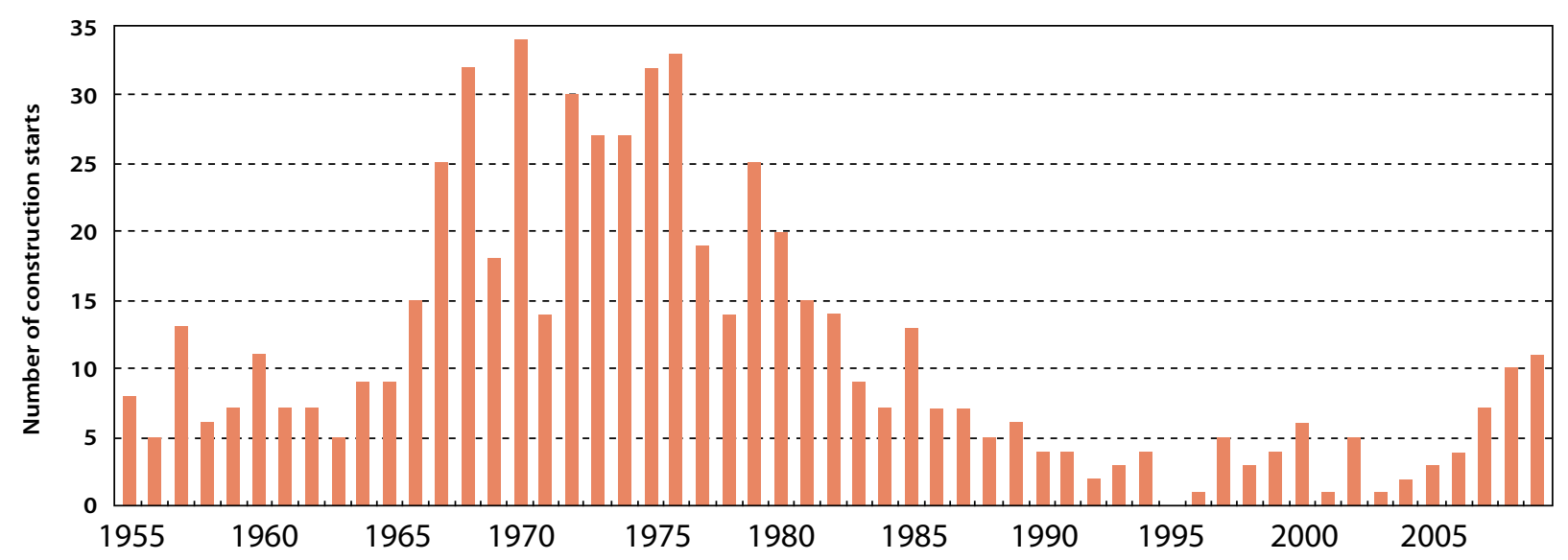

Fonte: IAEA PRIS 
TABELA 1

Reatores nucleares em construção (2010)

\begin{tabular}{|c|c|c|}
\hline País & & Total MW (elétrico) \\
\hline Argentina & 1 & 692 \\
\hline Brasil & 1 & 1.245 \\
\hline Bulgária & 2 & 1.906 \\
\hline China & 26 & 27.230 \\
\hline Finlândia & 1 & 1.600 \\
\hline França & 1 & 1.600 \\
\hline Índia & 4 & 3.564 \\
\hline Irã & 1 & 915 \\
\hline Japão & 2 & 2.650 \\
\hline Coreia do Sul & 5 & 5.560 \\
\hline Rússia & 11 & 9.153 \\
\hline Eslováquia & 2 & 782 \\
\hline Ucrânia & 2 & 1.900 \\
\hline Estados Unidos & 1 & 1.165 \\
\hline Total & $\mathbf{6 2}$ & $\mathbf{6 2 . 5 6 2}$ \\
\hline
\end{tabular}

medidas de segurança adicionais introduzidas após os acidentes de Three Mile Island e Chernobyl.

Após o ano 2002, o governo Bush, nos Estados Unidos, fez grande esforço para promover uma "renascença nuclear", acelerando a concessão de licenças e usando recursos públicos para compensar as empresas construtoras por atrasos ocorridos no processo de licenciamento e construção dos reatores. Desde 2005 a construção de novos reatores adquiriu um novo ímpeto com reatores na China, Rússia, Coreia do Sul e outros, como mostra o Gráfico 2.

O exemplo dado pelos Estados Unidos, acompanhado de uma forte campanha de marketing, levou cerca de cinquenta nações, incluindo países em desenvolvimento, a manifestar à Agência Internacional de Energia Atômica interesse em entrar na "era nuclear" instalando reatores em seus territórios. Após 25 anos, o acidente de Chernobyl parecia esquecido e uma renascença nuclear estava em curso. O número de reatores em construção em 2010 era de 62, distribuídos entre vários países, mas concentrados na China,
Rússia, Coreia do Sul, Índia e Japão, como indicado na Tabela 1 .

Em março de 2011, um forte terremoto, seguido por um grande tsunami, atingiu o nordeste do Japão e provocou sérias avarias em três dos seis reatores nucleares de Fukushima-Daiichi. Os fatos resultantes desses eventos são bem conhecidos: a perda de refrigeração nos reatores e nas piscinas onde os elementos combustíveis (altamente radioativos) fundiram e lançaram grande quantidade de radioatividade no are no mar. Aquantidade de material radioativo liberado é estimada em 40 vezes a que foi liberada pela explosão nuclear em Hiroshima, mas 10 vezes menor que a de Chernobyl. O desastre foi classificado no nível 7 - o mesmo de Chernobyl - e a população num raio de $20 \mathrm{~km}$ dos reatores teve que ser removida (cerca de 100 mil pessoas).

Como resultado, a confiança na segurança dos reatores nucleares, que havia sido recuperada após 25 anos sem a ocorrência de acidentes de vulto, foi abalada levando a uma reavaliação dos procedimentos de segurança em todo o mundo. Provocou-se 
também uma reavaliação do interesse em prosseguir no uso de reatores nucleares para a geração de eletricidade.

O setor nuclear tem tentado minimizar a gravidade do acidente de Fukushima usando basicamente dois argumentos:

1) $O$ acidente se deve a uma combinação extremamente improvável de um terremoto de grande intensidade seguido por um tsunami de proporções inesperadas. Esse argumento evita enfrentar a verdadeira natureza do problema, que é a interrupção do fluxo de água através do núcleo do reator (ver Apêndice). Dessa maneira, com o aumento da temperatura, as barras de combustível fundem liberando enormes quantidades de radioatividade. $\mathrm{O}$ fluxo de água é essencial para a retirada de calor, e seu uso para geração de eletricidade pode ser interrompido não apenas por terremotos e tsunamis, mas também por falhas mecânicas e erros humanos, como ocorreu no acidente de Three Mile Island, nos Estados Unidos, em 1979. É possível melhorar a segurança dos reatores para que esses problemas sejam corrigidos a tempo, mas não existe segurança absoluta, e acidentes podem sempre ocorrer.

2) $O$ número de mortes decorrentes da exposiçãoàradioatividadefoimuito pequeno, e um número muito maior de mortes ocorre em acidentes na extração de carvão. Esse argumento revela um desconhecimento da natureza dos efeitos da radiação nuclear sobre os seres vivos. Num acidente numa usina de carvão poderá morrer um certo número de pessoas mas elas são bem identificadas. Operários que trabalham numa mina têm consciência dos riscos que correm e em geral são remunerados para tal ou são cobertos por seguros. Quando ocorre um acidente nuclear, centenas de milhares de pessoas recebem doses pequenas de radioatividade, mas o efeito integrado da radiação nessas pessoas pode causar - estatisticamente mudanças genéticas. $\mathrm{O}$ fato de as pessoas não morrerem porque receberam doses pequenas de radioatividade não significa que muitos não morrerão mais tarde devido à radiação. Em Chernobyl estima-se que pelo menos 6.000 pessoas que viviam nos arredores da usina morreram de câncer nos dez ou vinte anos posteriores ao acidente. Existem também estimativas de que o número de mortos foi muito maior. Pessoas que recebem doses elevadas de radioatividade resultante de um acidente nuclear são vítimas involuntárias, não são remuneradas por viver perto de um reator e nem têm seguro. O sofrimentoe a inconveniência de centenas de milhares de pessoas deslocadas de suas residências por muitos meses, como ocorreu com os que viviam num raio de $20 \mathrm{~km}$ das usinas de Fukushima, são muito difíceis de quantificar em termos financeiros, mas já se tornou evidente que o ressarcimento oferecido pela Tepco (empresa proprietária dos reatores) é irrisório. Em Chernobyl, até hoje, decorridos 25 anos, existe uma área de exclusão de cerca de $3.000 \mathrm{~km}^{2}$, de onde a população foi permanentemente removida.

É possível melhorar o desempenho de reatores e torná-los mais seguros, mas isso vai acarretar custos mais elevados, o que tornará a energia nuclear ainda menos competitiva do que já é em relação a outras formas de energia elétrica.

A grande maioria dos reatores nucleares em uso hoje começou a funcionar 30 ou 40 anos atrás e forçosamente terá que ser "aposentada" em breve. Os reatores de Fukushima funcionavam há mais de 40 anos. Aredução da vida útil dos reatores diminuirá ainda mais sua competitividade econômica. Mais ainda, será preciso resolver de vez o problema do armazenamento permanente dos resíduos nucleares que se arrasta há décadas. Até hoje os elementos combustíveis usados - que são altamente radiativos - são depositados em piscinas situadas ao lado dos reatores, e um dos problemas em Fukushima foi a radioatividade liberada quando o nível da água da piscina baixou . Só nos Estados Unidos são 104 piscinas ao lado dos reatores lá existentes. Em Angra dos Reis também existe uma.

Finalmente há o problema de quem pagará pelas compensações para a população atingida pelos acidentes nucleares. Os limites fixados pelos governos para cobrir 
esses danos são atualmente muito baixos e deverão aumentar muito.

Por essas razões vários países já decidiram adotar uma "estratégia de saída gradual" da energia nuclear. Bélgica, Suíça e Japão cancelaram a construção de novos reatores ou decidiram desativar reatores em funcionamento quando atingirem o fim de sua vida útil (cerca de 30 a 40 anos). A China suspendeu também a concessão de licenças para a construção de novos reatores até que uma completa revisão das normas de segurança seja feita. A Alemanha foi mais longe ao tomar a decisão de desativar todos os seus 17 reatores, que fornecem $22 \%$ da eletricidade consumida no país, até 2022.

Como resultado dessas decisões, a Agência Internacional de Energia reduziu a sua estimativa de geração nuclear à metade para 2035. A previsão antes do acidente de Fukushima era a de que até 2035 a capacidade mundial instalada, que é hoje de cerca de 350 milhões de quilowatts, dobraria. Essa previsão foi reduzida em $50 \%$.

\section{ENERGIA NUCLEAR NO BRASIL}

À luz desses desenvolvimentos no exterior, o que se pode dizer sobre o papel da energia nuclear no Brasil? A Tabela 2 mostra a contribuição das diversas fontes de energia em 2010 e as projeções para 2019 do Plano Decenal de Energia da Empresa de Planejamento Energético e do Plano Nacional de Energia do Ministério de Minas e Energia.

A energia nuclear representou, em 2010, $2 \%$ da eletricidade produzida no país, contribuição que deverá aumentar para 3,4\% em 2019, com a entrada em funcionamento do reator Angra III a ser concluído em 2015. O Plano Nacional de Energia prevê a construção de quatro reatores nucleares além dos reatores Angra I, II e III, o que levaria a participação nuclear a 7,4\% até 2030 .

Uma das justificativas para expandir a contribuição nuclear à matriz energética brasileira é a de que ela supre eletricidade de base, complementando a geração

\section{TABELA 2}

\section{Fontes de energia primária (milhões de toneladas equivalentes de petróleo)}

\begin{tabular}{|c|c|c|c|}
\hline Fontes & $\mathbf{2 0 1 0}$ & $\mathbf{2 0 1 9}$ & $\mathbf{2 0 3 0}$ \\
\hline Hidroelétricas & $\mathbf{7 7 , 0}$ & $\mathbf{1 1 0 , 0}$ & $\mathbf{1 4 4 , 6}$ \\
\hline Térmicas & $\mathbf{2 3 , 1}$ & $\mathbf{2 8 , 8}$ & $\mathbf{4 2 , 6}$ \\
\hline Gás natural & 11,3 & 11,5 & 17,5 \\
\hline Nuclear & 2,0 & 3,4 & $\mathbf{7 , 4}$ \\
\hline Carvão & 1,6 & 3,2 & $\mathbf{4 , 9}$ \\
\hline Outras & 8,2 & 1,7 & $\mathbf{4 4 , 8}$ \\
\hline Alternativas & $\mathbf{1 , 3}$ & $\mathbf{2 8 , 2}$ & 9,0 \\
\hline Hidroelétricas & 3,6 & 7,0 & 13,5 \\
\hline Eólica & 0,9 & 6,0 & $\mathbf{2 2 , 3}$ \\
\hline Biomassa & $\mathbf{7 , 8}$ & $\mathbf{8 , 5}$ & $\mathbf{4 , 0}$ \\
\hline Importação (Itaipu) & $\mathbf{5 , 7}$ & $\mathbf{6 , 7}$ & $\mathbf{2 3 6 , 0}$ \\
\hline Total & $\mathbf{1 1 8 , 1}$ & $\mathbf{1 7 3 , 7}$ & \\
\hline
\end{tabular}


hidroelétrica, que varia sazonalmente. Outras fontes térmicas, como carvão, gás natural e eletricidade gerada com bagaço de cana, no entanto, estão na mesma categoria. Outra justificativa é a de que as reservas de minério de urânio do Brasil para geração nuclear são elevadas (cerca de 300 mil toneladas de óxido de urânio), a um custo inferior a 130 dólares/kgU, o que poderia conduzir o país à autossuficiência nessa área ou até levá-lo a se tornar um exportador de urânio. Apesar de apreciáveis, as reservas brasileiras representam apenas $6 \%$ das reservas mundiais. Além disso, o óxido de urânio não é combustível de reatores nucleares, mas tem que passar por um longo processo de produção e "enriquecimento" no isótopo U235 até que possa efetivamente ser usado nos reatores, como consta no Plano 2030.

O Brasil domina a tecnologia do ciclo do combustível, inclusive a principal fase, que é o enriquecimento. A primeira fase da unidade de enriquecimento, de Resende, cuja conclusão é prevista para breve, deverá suprir 60\% do combustível consumido nas usinas de Angra I e II. Contudo, o enriquecimento de urânio exige instalações consideráveis, cujo custo de capital é de cerca de 1 bilhão de dólares. Uma carga típica de reator como o de Angra II custa cerca de 10 milhões de dólares no mercado internacional. É por essa razão que, para

\section{APÊNDICE}

O uso da energia nuclear para a produção de eletricidade foi um subproduto do desenvolvimento das armas nucleares com fins militares durantee apósaSegunda Guerra Mundial(1939-45).Aenergia nuclear não é baseada na energia mecânica nem na energia química (como na queima dos combustíveis fósseis). A fonte da energia nuclear é a desintegração dos núcleos de átomos de urânio, que libera uma quantidade considerável de energia na forma de energia cinética dos fragmentos como estrôncio ( $\mathrm{Sr}$ ) e xenônio (Xe), que, em geral, são radioativos. Esse processo é chamado de fissão nuclear e pode ser produzido bombardeando-se átomos de urânio com projéteis adequados como nêutrons (Figura 1).
FIGURA 1

\section{Fissão do urânio em estrôncio e xenônio}

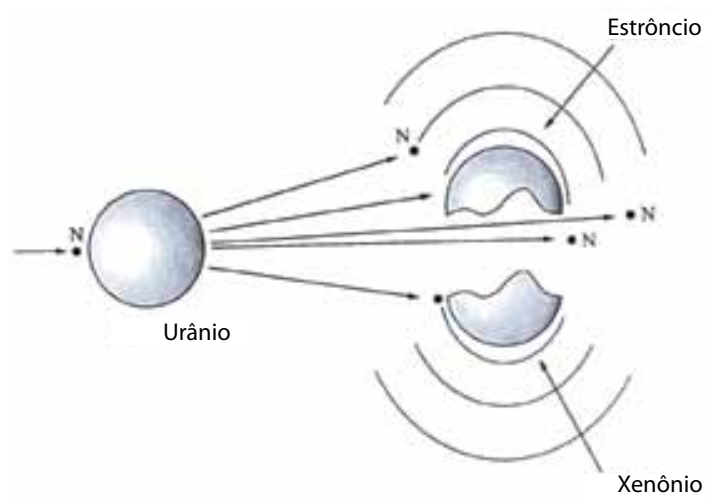

justificar a construção de uma unidade de enriquecimento, que custa 1 bilhão de dólares, seriam necessários pelo menos dez reatores nucleares em funcionamento. Caso contrário, valeria mais a pena comprar o urânio enriquecido no mercado internacional, onde a capacidade de enriquecimento supera o consumo atual no mundo, havendo, portanto, capacidade ociosa.

Esse é um argumento de natureza puramente econômica. Para alguns países a garantia de independência nacional nessa área poderia exigir a capacidade de produzir seu próprio urânio enriquecido. Esta, contudo, é uma opção política e não econômica.

É evidente que o Brasil tem amplas oportunidades de produzir a energia de que necessita sem a presença de um grande parque de reatores nucleares, e a reavaliação do Plano Nacional de Energia em curso aponta claramente para a redução da contribuição nuclear, em sintonia com o que está ocorrendo no resto do mundo.

A “queima" de $1 \mathrm{~kg}$ de urânio libera a mesma quantidade de energia que 16 mil toneladas de um combustível fóssil.

Na fissão nuclear são emitidos nêutrons e radiação gama. Os fragmentos finais, que são radioativos, constituem os rejeitos nucleares, um dos problemas mais sérios resultantes do uso desse tipo de energia.

Na fissão de um átomo de urânio por um nêutron são produzidos outros três 
nêutrons que, por sua vez, podem provocar outras fissões dando origem a uma reação em cadeia que leva à fissão de um número enorme de outros átomos. Se esse processo ocorrer rapidamente, ele dará origem a uma explosão nuclear, que é basicamente um grande número de átomos de urânio fissionando-se num curto espaço de tempo (Figura 2).

É possível também “queimar” o urânio lentamente, o que aquece a centenas de graus as barras de urânio. Nos reatores a água fervente (BWR), a água circula em torno dessas barras, retirando seu calor, e se converte em vapor superaquecido, que aciona uma turbina, gerando eletricidade da mesma forma que numa termelétrica convencional, em que a fonte de calor é a queima de carvão, petróleo, gás ou biomassa (Figura 3).

Nos reatores a água pressurizada (PWR), que são os mais utilizados no presente, a água é mantida em alta pressão e não ferve, mas seu calor é transferido a um sistema secundário através de trocadores de calor. Nesse sistema a água se vaporiza e move as turbinas.

A preparação do urânio requer um “ciclo de combustível" completo, desde a extração e purificação dos sais de urânio e a sua conversão em um gás, até o "enriquecimento" do urânio no isótopo fissionável U235. O U235 constitui apenas $0,7 \%$ do total, sendo o restante U238. É necessário utilizar uma mistura de urânio com pelo menos $3 \%$ de U235 na maioria dos reatores nucleares comerciais. O enriquecimento consome

\section{FIGURA 2}

\section{Reação nuclear em cadeia}

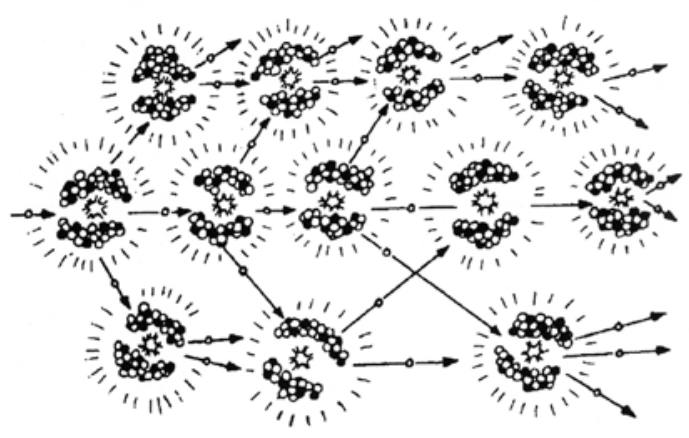

FIGURA 3

\section{Energia termelétrica gerada por meios convencionais e por usina nuclear}
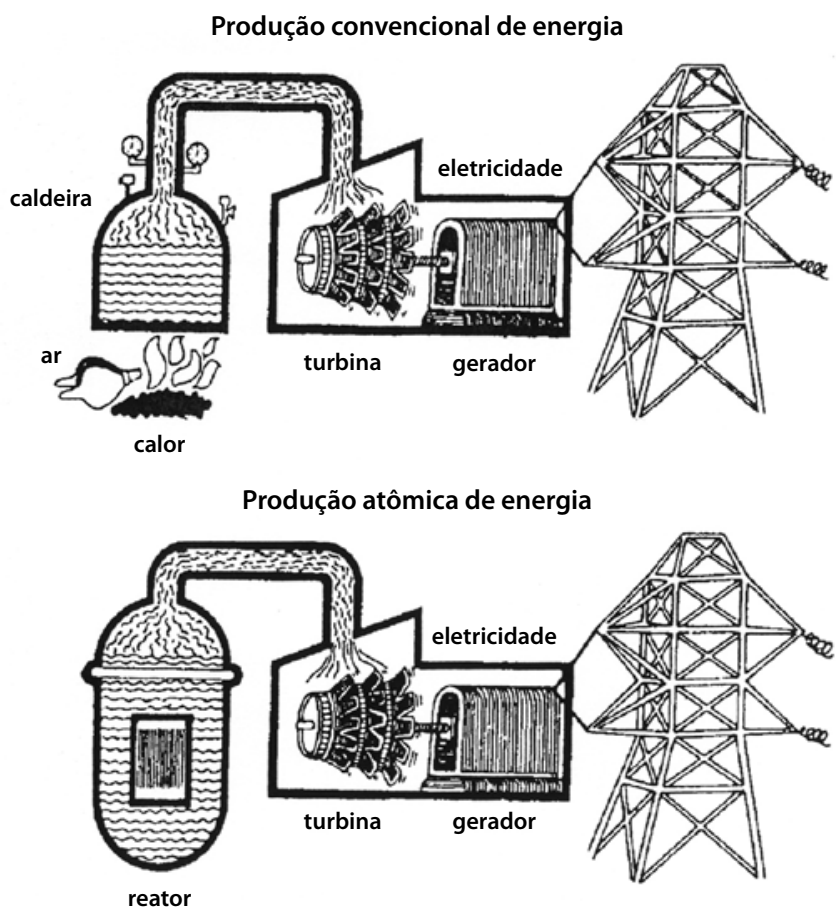

grandes quantidades de eletricidade e, assim, dependendo da origem dessa eletricidade, a emissão de poluentes pode ser significativa nesse processo.

Uma das características mais interessantes da geração de eletricidade com reatores nucleares é a pequena quantidade de combustível necessária para a operação das usinas. Uma usina termelétrica de um milhão de quilowatts, queimando carvão - as quais existem muitas no mundo -, necessita de 2 a 2,4 milhões de toneladas de carvão por ano. Um reator nuclear, apenas trinta toneladas de urânio. Isso se deve ao fato de que a energia liberada pela fissão nuclear é milhões de vezes maior do que a liberada nas reações químicas.

A produção de energia nuclear não resulta em emissões de gases responsáveis pelo aquecimento da Terra, que é o caso quando se produz energia elétrica com combustíveis fósseis, como carvão ou gás natural. As preocupações com o "efeito estufa" levaram vários ambientalistas a apoiar uma "renascença nuclear". 